\title{
Programa de formação continuada para conselheiros da área da infância e juventude ${ }^{1}$
}

\section{Antônio José Ângelo Motti *}

A formação continuada é um desafio muito grande para todos nós. No ano de 2013, nossa experiência no Mato Grosso do Sul completará 15 anos. Durante esses anos, formamos conselheiros em Campo Grande para o Mato Grosso do Sul e também para outros lugares do Brasil. É um desafio enorme pensar na concretude da expressão de formar continuadamente conselheiros.

Na nossa prática, e para a própria política pública, formar continuamente deve ser uma meta. E, como dizia a Doutora Carmen Silveira, ex-secretária Nacional de Proteção dos Direitos da Criança e do Adolescente, é preciso superar a tendência da maioria dos cursos que são muito rápidos, breves, conhecidos como "cursos Walita". São cursinhos que os fabricantes de eletrodomésticos dão para você saber manusear o aparelho, para melhor utilizá-lo na sua cozinha.

Para nós, da área dos Direitos Humanos, esses cursos não servem, não serviram e não tem serventia. Na Escola de Conselhos da Universidade Federal de Mato Grosso do Sul (UFMS),

\footnotetext{
${ }^{1}$ Palestra proferida na Universidade Estadual de Londrina (UEL) no marco da Curso de Capacitação Permanente de Conselheiros Tutelares e Conselheiros de Direitos.

* Psicólogo. Coordenador da Escola de Conselhos da UFMS.
} 
iniciamos pensando em um ideal. Nesse sentido, pensamos que um conselheiro tinha que conhecer tudo que diz respeito à infância e à juventude. Nosso primeiro curso teve uma carga horária de 320 horas-aulas. O curso tinha um ano de duração, ou seja, pode ser quase equiparado a um curso de especialização e a um curso de aprofundamento, de aperfeiçoamento. Esse primeiro curso foi oferecido para 80 alunos. Apenas 35 conselheiros concluíram o curso. Surge um primeiro desafio: como vencer a descontinuidade do processo de participação? Como e o que fazer para que o número de concluintes de um curso dessa natureza seja mais expressivo?

No segundo curso promovido, foram abertas 120 vagas. Desse total de inscritos, apenas 45 conseguiram concluir. Tais resultados nos levaram a refletir se não era muito investimento financeiro público para poucos resultados. Mas o resultado principal não é garantir a presença da maioria dos inscritos até terminar o curso? Não, não é. Com certeza não é! Quando se pensa em formar alguém para o exercício de uma função, o resultado não é a frequência dessa pessoa no curso e ser certificado por isso. Esse não é o resultado. O resultado deve ser a possibilidade de essa pessoa exercer bem a sua função, exercer todas as atribuições e competências inerentes a essa, e ter como conseguir aplicá-las quando for necessário. Toda vez que necessitar, ela tenha a quem recorrer, pois entendemos que no processo de formação devem ser oferecidas informações de como acessar suportes para orientações.

Bom, então vamos pensar como que é isso.

Então, por que a gente pensa em formação? Vamos refletir um pouco sobre a nossa história recente.

Ora, a Constituição de 1988 estabelece em vários artigos que o poder é do povo, e em seu nome deve ser organizado.

Qual a história do Brasil nesse sentido? É uma história de luta. A história do Brasil no campo do poder da sociedade é uma história de luta. A conquista no papel se deu a partir de 1988. O poder foi estabelecido como poder do povo e, em vários momentos dessa 
Constituição, foi estabelecido como é que se daria este processo de exercício de poder do povo, do controle do povo sobre o poder público, formando o chamado Estado, visto por Gramsci como resultado de sociedade + poder público. Gosto dessa visão e não consigo ver o Estado sem o povo.

Então, como é que se dá o controle do povo, da sociedade sobre o poder público? Como é que sociedade controla? Como é que participa? Em vários de seus artigos, a nossa Constituição trouxe os elementos para que se pudesse estabelecer de fato esse poder.

Bom, mas qual o conhecimento que as pessoas têm disso? Qual o conhecimento prévio? O sujeito que é convidado a compor um conselho sabe dessas premissas, dessas prerrogativas? Sabe ele da existência de um arcabouço legal que deve orientar toda a nação brasileira, onde estabelece que o poder esteja na mão do povo e que o povo deva exercer esse poder de forma direta, de forma representada, de forma delegada?

A democracia participativa é estabelecida quando, então, o cidadão ocupa os lugares nos conselhos representando segmentos, interesses. Também está estabelecida a democracia representativa quando escolhemos pessoas para representar nossos interesses. Diante disso, indagamos novamente: qual é a concepção que nós, povo brasileiro, temos disso? Nenhuma? Quando se pertence a um Conselho, tem-se a noção de estar lá exercendo o poder?

Na realidade, maior parte, as pessoas frequentam porque são delegadas por alguma instituição, sem muitas vezes serem consultadas, se há interesse em representar um determinado segmento suas ideias, suas demandas. Não é assim que se processa em grande parte dos casos?

- "Você gostaria de participar do Conselho Municipal dos Direitos da Criança?".

- "Ah, quero sim, mas o que é o Conselho da Criança?".

- "O Conselho Municipal é um negócio que cuida de crianças".

- "Tá bom, então é criança, vamos lá!". 
Poucos reconhecem no Conselheiro Tutelar o poder da sociedade, pois por estar vinculado a um órgão público parece que não pertence à sociedade. Como quem paga o salário dele é a prefeitura, o Conselheiro não é visto como um agente da sociedade, como quem exerce o poder do povo na administração do direito da criança.

Por outro lado, por que a pessoa se torna Conselheiro Tutelar? Há várias razões: desde desemprego, de gostar de criança ou até pelo fato de ter estagiado em algum projeto nessa área. Nesses casos, a pessoa pode fazer esse trabalho como uma escolha de vida, uma ocupação diferencial, talvez bem melhor preparado do que aquele sujeito comum da sociedade que nunca refletiu sobre isso.

O Conselho Tutelar foi uma resposta legal que concretiza o poder da sociedade de gerir administrativamente seus problemas na área da infância, tirando esse papel que era da justiça e realocando como uma função da sociedade resolver, nesse caso, representado por cinco pessoas. Isto é, na prática e é a prática do poder do povo. Mas, perguntamos aqui também: o conselheiro chega com essa informação no início das suas funções?

Quando um conselheiro faz um curso, ele pode ter acesso a todas as informações, no entanto, isso pode se tornar apenas repasse de informações, porque o sujeito não se apropriou do significado prático. Quando não se apropria, vira só uma fase, cujas informações são usadas quando convém, mas não se apropria na prática, no cotidiano.

A Constituição é o lastro quando se pensa na formação continuada, trazendo um desafio enorme: empreender suas premissas e estabelecer uma nova cultura. É coerente dizer que a nossa cultura está na contramão dessas concepções e, para ser implantada uma nova cultura, muitos teriam (e terão) que abrir mão de privilégios e do poder que as velhas tradições trazem para aqueles que ocupam a direção de um órgão, de funções importantes na história do país.

Como, de certa forma, poucos quiseram se informar direito ou mobilizar as pessoas e as instituições sobre isso, mudar as práticas e, por consequência, a realidade se tornou um desafio da capacitação, como se a capacitação fosse capaz de dar conta desse processo. 
Então, ficamos nós, os realizadores das capacitações, com o desafio de transformar a realidade. Não se transforma a realidade numa capacitação, o que transforma a realidade é a prática das pessoas. Para ter prática, é preciso ter a consciência sobre aquilo que será feito. Segundo o saudoso Antônio Carlos Gomes da Costa, nas palavras de Edson Seda, "nós temos que mudar a maneira de ver, pensar e agir". Se isso se processa de fato, a realidade poderá ser alterada. Se você não vê a criança e seus interesses de forma diferente do que estabelecem as velhas tradições, vai continuar pensando e agindo pelas tradições vigentes, agindo no automático, reproduzindo as práticas que afastam a sociedade do seu poder e, por consequência, das suas obrigações.

Quanto mais distante tiver a sociedade disso, mais absoluto é o poder daqueles que governam em nome do público. Os dirigentes decidirão, sobretudo segundo suas visões, a experiência pessoal e/ou conveniência. Como não terão que dividir o poder com a sociedade, as instituições públicas continuarão a tutelar a sociedade, e, quando contemplam a participação dessa, coloca-a para decidir a seu favor. É preciso promover um choque de cultura. E a capacitação dá conta disso? Não dá, com certeza. Uma formação continuada dá conta disso? Por si só não, no entanto, constitui-se em um grande instrumento para promover a transformação da consciência, da forma de ver e, por consequência, de pensar e agir.

Porém, é necessária a disposição pessoal. Não adianta vir para o campo das políticas públicas pessoas que não têm nenhuma intenção na transformação da realidade dos direitos da criança e do adolescente. Para a criança, de nada adianta ter, nesse campo, pessoas que buscam apenas um trabalho formal, gente que precisa de emprego, gente que quer o status. Então, a formação, com certeza, não vai ao encontro desses.

Podemos indagar: quem tem controle sobre aqueles que vêm para o campo dos direitos e dos interesses da infância? Ninguém tem controle sobre isso. Nem o Conselho Tutelar, nem o Conselho de Direitos. Mas isso é trágico? Não! Isso é real! Perante o direito da criança, não ter controle sobre isso soa como surreal, mas isso é real. 
Como é que se pode controlar a qualidade de quem vem para essa área? Penso que o tempo vai nos responder sobre essa indagação. Logicamente que o processo de formação sempre teve e sempre terá uma capacidade de responder à atribuição de melhorar a qualidade dos serviços destinados a essa área. Dessa forma, quanto mais pessoas tomarem conhecimento sobre as questões relacionadas aos direitos da criança, quanto mais pessoas tomarem consciência a respeito da amplitude, do significado e do que estabelece o novo direito da infância e adolescência no Brasil, com certeza, maior resistência será criada àqueles que não têm nada a ver com esse campo.

Quanto mais pessoas tomarem consciência a respeito da amplitude, do significado que diz o novo direito da infância e adolescência no Brasil, maiores as possibilidades de se criar um campo positivo, preparado para esse processo. Para tanto, temos que trabalhar, concomitantemente, com o conjunto das políticas públicas para criar esse ambiente necessário.

A doutrina da Proteção Integral trazida pela Convenção Internacional dos Direitos da Criança estabelece uma série de princípios que as sociedades e os países devem buscar garantir em direção ao atendimento dos interesses de crianças - no caso da Convenção, crianças são as pessoas de até 12 anos. Esses princípios ordenam as ações necessárias para se realizar ou garantir a efetivação do pleno desenvolvimento da criança em condições de igualdade e a proteção diferenciada, pelo fato de estarem em desenvolvimento.

A Convenção Internacional deve ser conhecida por todos de forma mais ampla e devemos ocupar todos os espaços para falar mais da Convenção. Nós devemos é mostrar a todos que os princípios constitucionais brasileiros não foram invenções tupiniquins. O Brasil seguiu uma corrente internacional de entendimento dos Direitos Humanos infantojuvenis, que refletia na necessidade de uma mudança radical na realidade brasileira, até porque a realidade brasileira trazia o avesso da Convenção. 
Precisamos estabelecer um entendimento de que a doutrina que protege os direitos da criança não seja vista pelas pessoas apenas como algo que muda responsabilidades, que ameaça a estabilidade das pessoas, como quiseram fazer e fazem até hoje, em relação ao Estatuto da Criança e do Adolescente.

No caso brasileiro, por exemplo, o Estatuto foi e é usado nas escolas como instrumento de ameaça aos educadores; é usado na área da saúde como instrumento de ameaça aos profissionais de saúde; é usado na área de segurança pública como instrumento que descredibiliza e ameaça as forças de segurança. Fica evidente que não há uma associação natural de que o Estatuto é o reflexo da nossa convenção maior - a Constituição Federal, aprovada um ano antes da Convenção Internacional. Novamente perguntamos: qual é a formação que a gente tem sobre isso?

Não se pode pensar numa formação continuada de conselheiros sem levar em conta a importância da Convenção Internacional, e como ela tem sido apropriada pelas pessoas que vão trabalhar com um campo do atendimento, da promoção, da proteção e da defesa dos direitos da criança e do adolescente. A convenção é peça obrigatória e não deve ser peça de um discurso retórico. Deve ser apropriada por todos os ambientes públicos, pelos professores, pelos profissionais de saúde, pelos profissionais de segurança, de cultura, de esporte, e é um instrumento riquíssimo que cada vez que se lê muito se aprende. É encantador pensar como que o ser humano teve a capacidade de estratificar aqui a compreensão de que a criança é um humano criança, o que implica a sua existência para todos os humanos.

A Convenção nos coloca uma série de obrigações. Na qualidade de país signatário, todos aqueles que estarão executando as ações decorrentes dos compromissos assumidos devem estar qualificados para o exercício das suas funções. Assim, formar continuadamente é um compromisso que o Brasil assumiu quando assinou a Convenção, e o Governo brasileiro o fez em nome do povo brasileiro e não só das estruturas públicas. 
Quantas são as políticas públicas que atendem os interesses e direitos das crianças, tomando por base os princípios da Convenção? Quantas são as políticas públicas que se referem à Convenção na fundamentação dos seus programas, projetos e ações. Então a formação requer transformação.

O artigo 4을 do Estatuto e o artigo 227 da Constituição estabelecem a prioridade no atendimento aos direitos da criança, a primazia, o privilégio na destinação de recursos e na elaboração de políticas. Mas, podemos perguntar: adianta elaborar uma política ou estabelecer serviços de atendimento aos direitos de crianças e adolescentes se as pessoas que vão executar não estão formadas para as funções decorrentes?

Vamos fazer essa reflexão tomando, por exemplo, o Centro de Referência Especializado de Assistência Social (CREAS), um exemplo bem prático. Eu trabalho na formação do CREAS no meu Estado, ou melhor, no desafio da formação dos profissionais que atuam no CREAS desde seu início. Nossa atuação nessa área iniciou quando, no começo do século XXI, foram implantados os Centros de Referência do Programa SENTINELA, do qual tive o prazer de ser idealizador e implantador no Brasil.

Quando implantamos o Programa SENTINELA, tínhamos um desafio. Sua ação estava baseada em um Centro de Referência para atender às vítimas de violência sexual, composto por uma equipe multidisciplinar, introduzindo na política da assistência social a figura do profissional em psicologia. Era sabido e de amplo conhecimento que no processo de graduação dos cursos de formação superior, não se formava profissionais especializados para atender às crianças vítimas de violência sexual. À época, fomos dividir essa preocupação com o Conselho Federal de Psicologia, mobilizando-o para que se ocupasse disso. Nos últimos doze anos, o Conselho produziu uma série de documentos de orientação de como os psicólogos poderiam trabalhar com crianças vítimas de violência sexual, com adolescentes infratores e com a população atendida pela assistência social, básica e/ou especial. 
Então, além de estabelecer políticas que atendam a princípios da primazia, do privilégio, é preciso assegurar que as políticas sejam de qualidade. E o dever que tem a política de qualidade? Vai depender da formação, e questões condizentes aos direitos violados requerem uma formação acima daquela formação geral. É necessária uma formação específica, ultraqualificada, como é o caso do atendimento a uma criança vítima de violência sexual. Se isso vale para o CREAS, vale para o Conselho Tutelar, que atende a essa mesma criança, bem como para um policial que vai registrar os fatos que envolveram a violação, ou mesmo para o perito que vai construir um laudo, o juiz que vai julgar etc.

De nada ou pouco vale cumprirmos a obrigação legal da destinação privilegiada de recursos se destinarmos os recursos só para as despesas físicas dos serviços. De nada ou pouco valerá nossa ação se não garantirmos que as pessoas que atuarão nos serviços tenham a qualificação necessária para o exercício de suas funções.

Levando isso em conta, a nomeação de conselheiros tutelares deveria ser antecedida pela formação. Como é que uma pessoa sem formação para a função pode ser nomeada conselheiro tutelar e no outro dia exercer autoridade para estabelecer medidas de proteção?

Muitos de nós tememos, às vezes, o resultado desses atos. Esse receio vale para nomeação de Conselho Municipal de Direitos, principalmente porque o Conselho Tutelar vai agir todas as vezes em que os direitos forem violados, estabelecendo medidas previstas no artigo 101 do ECA, e, muitas vezes, os serviços decorrentes de sua ação não existem, não funcionam ou são insuficientes.

Quem é que regula a política municipal de atendimento aos direitos da criança e do adolescente? O Conselho Municipal.

E se ele não está formado para isso? Ele regula o que? Nada.

O que é que o Conselho Tutelar vai ter à sua disposição? Nada. 
Então, a formação é essencial. Um curso de capacitação deve ser entendido como uma das etapas da formação. A formação deve ser continuada.

No artigo 86, está estabelecido o sistema integrado de atendimento da criança e do adolescente. Todas as ações dirigidas à criança e ao adolescente devem ser integradas e articuladas, rompendo com a velha tradição em que determinados setores se encarregavam de promover todas as necessidades da criança, a exemplos das FEBEM'S.

A extinta Fundação Nacional do Bem-estar do Menor (FUNABEM) era, até 1990, o órgão nacional responsável pela coordenação da Política Nacional do Bem-Estar do Menor. Ela fazia o que propunha para aquela época: apoiar os Estados para implantar serviços que dessem conta de todas as necessidades básicas dos seus assistidos nas FEBEM'S. Existiam unidades da FEBEM que possuíam em sua sede hospital, oficinas, escola, alojamento, igreja, campo de futebol, quadras de esporte, ginásio, cinema, teatro. Eram ilhas de serviços que isolavam as crianças do convívio com a sociedade.

O artigo 86 veio para romper com isso. Decorrente dele a criança é entendida como um sujeito de direitos e um cidadão absoluto, devendo ter seus direitos atendidos por um conjunto de políticas e ações. Pressupõe que os atores desse processo possuem a formação para o exercício e desempenho das funções. O artigo 86 obriga-nos a fazer a integração das capacidades das competências de tal forma que nenhum dos serviços responda pelas necessidades das crianças, mas no conjunto das competências.

Vamos fazer algumas reflexões. Adianta estruturar um serviço de apoio psicológico para quem não foi treinado para apoiar psicologicamente crianças e adolescentes e famílias? Adianta ter um Conselho Municipal composto por quem não tem informação para ser conselheiro? Adianta ter um Conselho Tutelar composto por quem não tem formação para exercer suas funções e autoridade?

Não, a resposta é NÃO, pois a formação é uma condição prévia. 
Dessa forma, podemos fazer uma comparação com as exigências de diversas ocupações a exemplo daqueles que desempenham funções de segurança pública, saúde, habitação, obras etc. Dessa forma, podemos perguntar se o prefeito pode designar quem ele quiser para compor um conselho. Pela lógica, ele deve indicar para um conselho de saúde profissional com formação ou com comprovada atuação em saúde, principalmente pela inexistência de exigência legal de formação anterior ou formação prévia. Quando você tem o poder de indicar, você tem a responsabilidade de bem indicar. $O$ poder do povo que está estabelecido nos conselhos deve nos obrigar a essa responsabilidade dos formados.

Então, o artigo 86 remete a uma série de responsabilidades, uma vez que a atenção integral e articulada aos direitos da criança vai exigir informação de todos. Tanto daqueles que cuidam das diretrizes que orientam a rede como daqueles que acionam essa rede. É importante para nós, que temos vivido nesses anos pós-constituição, pós-ECA, pós-LOAS, pósLDB, os anos que sucederam regimentando essa capacidade natural que a sociedade tem de decidir sobre o poder, sobre as políticas.

Como é que essa dinâmica vem se estabelecendo com o passar dos anos? Nós temos a criação dos conselhos mais como decorrente das exigências dos repasses de recursos e das normas das políticas e das leis, do que por uma consciência real da sociedade e do poder público na necessidade de criá-los. Em grande parte dos casos, o motivo que leva ou levou os executivos municipais a enviarem projetos-lei paras as Câmaras, visando à criação de conselhos e dos governos do Estado em apresentarem seus projetos junto à assembleias, esteve vinculado a quê? Há muito mais razões vinculadas a uma exigência de repasse de recursos do que a consciência sobre o que significa você ter o controle social estabelecido e efetivado no seu território.

A criação dos Conselhos Tutelares sofreu muito essa influência. Tanto que no Brasil ainda não se tem a totalidade dos municípios brasileiros com Conselho Tutelar. Existem mais Conselhos Municipais do que Conselhos Tutelares. Aquele município que não recebe recursos diretos, repassados fundo a fundo, não se obriga a criar o Conselho Municipal e o Tutelar. 
A realidade brasileira não mostrou, nesse processo, uma transformação cultural de se poder estabelecer um poder da sociedade de maneira definitiva. A realidade brasileira se sujeitou à dinâmica do capitalismo: poder está sempre vinculado ao recurso financeiro. Associou-se o poder do povo ao poder financeiro, mas o povo não consegue alcançar o financeiro do poder. Sua participação viabiliza a finanças para o poder, quando se sujeita a compor os conselhos para viabilizar recursos federais para o município e para o Estado.

Dessa forma, os conselhos têm sido, em grande parte, instituições prefeiturizadas. Há uma prefeiturização do controle social e, às vezes, isso chega a ponto de se ter um conselho com toda a sua composição tutelada, manipulada pelo poder público local. Como não se tem consolidada uma cultura de participação da sociedade, como não se tem a formação do povo para isso, como nesses vinte anos nós não conseguimos produzir instrumentos em que a sociedade acessasse a isso e se apossasse desse poder, então, o velho poder público, ocupado por novos integrantes, repete as velhas tradições de tutelamento, manipulação e prefeiturização, ou seja, estatização dos ambientes de controle social. Essa estatização inclui o Conselho Tutelar.

O Conselho Tutelar exerce o controle social de uma forma muito específica: controla o dever do poder público e da sociedade, dos pais, dos responsáveis, dos vizinhos, dos professores, de todo mundo, em relação ao direito da criança. Se prefeiturizado, o Conselho Tutelar não controla nada. Essa relação tem sido uma relação absurda. Esta é a realidade brasileira.

Mas a formação continuada de conselheiros dá conta disso? Ela vai ter um grau de eficácia se estiver inserida em uma política de formação permanente, uma política que coloca à disposição da sociedade e das pessoas que têm interesse em participar desse processo. Todo conhecimento, informações e instrumentos para ela se apropriar, formar a sua consciência e a reagir, quer dizer, ver, pensar e agir. 
O que é a formação continuada? Para nós do Programa Escola de Conselhos da Universidade Federal de Mato Grosso do Sul é um sonho, desde a sua criação. Nós alcançamos? Em que pese nosso esforço, ainda não alcançamos. Para se ter uma ideia, era um instrumento que criamos de comunicação permanentemente com os Conselhos colocados à disposição do conselheiro municipal e tutelar. Depois de dois anos, ele foi desativado porque ninguém usava. Ninguém usava.

A formação implica disponibilizar instrumentos tecnológicos de última geração, porém, sozinhos, esses artifícios não garantem sucesso. É preciso instrumentalizar as pessoas, do ponto de vista do conhecimento, da informação e da tecnologia, uma vez que há inúmeros conselheiros que não sabem ligar um computador. Se fizermos um seminário sobre tecnologia de formação continuada, explorar o máximo possível de tudo isso, do ponto de vista do conteúdo, da metodologia e dos recursos, vamos constatar que existe uma gama enorme de possibilidades que nos conduzem a um sucesso. Mas o que me chama atenção é a palavra "continuada". Portanto, "continuada" depende de duas ações: uma ação própria de cada sujeito e uma ação do outro. Isto implica estar interessado, de querer, de perceber, de ter a noção das responsabilidades decorrentes, e se organizar para responder as demandas.

Para ficarmos menos suscetível a esse processo todo, dessa relação dicotômica que o poder público tem com a sociedade, como se ele fosse composto por pessoas que nunca foram da sociedade, temos que criar recursos técnicos e tecnológicos: 1) trabalhando com módulos presenciais, aqui e em outras cidades; 2) fazer orientação à distância 3) disponibilizar informações sistematizadas em publicações, artigos, revistas, fóruns.

No tocante a responsabilidade dos conselheiros, temos a experiência de uma situação que demonstra uma falta grave nesse sentido: ao término do penúltimo curso promovido, o prefeito enviou uma carta para a escola solicitando uma cópia da folha-ponto dos conselheiros. A escola examinou e percebeu o seguinte: que em dois módulos em que pagou a diária para o conselheiro não constava sua presença na folha de presença do curso. Isso infelizmente 
acontece muito e não tem tecnologia que dê conta disso. Essa é uma relação de troca, de obrigações, de deveres.

E quem é que deve estar por trás disso iluminando a atitude do Conselheiro? É um interesse superior da criança e do adolescente. Se não tivermos isso como iluminador das nossas atitudes, do nosso comportamento, da nossa ação, não vai adiantar de nada. Então prevalece o interesse escuso. Devo me capacitar porque a criança tem o direito de ter pessoas capacitadas para o atendimento dos seus direitos. É um direito da criança, de qualquer criança, e não somente da criança pobre. Aliás, essa eterna associação dos conselhos com a ideia da pobreza é a coisa mais pobre que nós inventamos no campo do atendimento à criança no Brasil, pois prevalece a tradição de soluções pobres para as crianças pobres. Se fossem vistas como pessoas plenas de direitos, as soluções às suas demandas teriam toda sofisticação de quem tem a solução para as crianças que não são pobres. Teriam disponíveis todos os recursos e as soluções que as crianças que não são pobres têm na solução de seus problemas. Então vamos parar com essa tradição, temos que romper com essa ideia.

Mas o que alimenta esse processo é vinculação, em lei, do Conselho Tutelar à área da Assistência Social. Pior ainda a vinculação do Conselho Municipal na Secretaria de Assistência. Como se fosse o Conselho Municipal da Assistência Social da Criança e do Adolescente. Uma visão distorcida, embora a Assistência Social seja carro-chefe da promoção das pessoas. É por tradição, pela velha tradição. Quem tinha que ser o carro-chefe desse processo? Quem mais passa tempo com a criança, na vida da criança? Qual é a política pública na qual a criança passa mais tempo em seus serviços. Isso mesmo, a Educação! E quem é que dá conta dos grandes desafios da infância? É a educação ou é a assistência? Na prática, na realidade, é a Assistência Social.

Sendo assim, o Conselho Tutelar não pode ter esse olhar, desculpe a expressão, "olhar vesgo", mirar para um lado, só enxergar a Assistência Social. Tem Conselho Tutelar que não faz nada sem passar pela Assistente Social. Portanto, isso é uma questão de formação. 
Outro aspecto importante é observarmos que tem Conselho que só existe no papel. Conselho Municipal que só existe no papel tem aos montes, aquele que só se reúne para eleger o Conselho Tutelar. Esse está com seus dias contados, pois a eleição do Conselho Tutelar agora vai ser nacional, ou seja, o Conselho Municipal vai ser o próprio condutor desse processo. Ele vai dar as coordenadas lá no dia da eleição e não apenas para marcar o dia da eleição. Por falar nisso, vocês já pensaram no impacto desse fato? Imaginem quando a Rede Globo, o SBT, a Record e a Bandeirantes, os canais mais assistidos, anunciarem que no dia tal o Brasil inteiro vai escolher os Conselhos Tutelares. Vocês já pensaram nisso? É quase o efeito da fumaça na Capela Sistina. A eleição do Conselho Tutelar feita num dia só significa que Brasil vai anunciar uma nova era. Nós temos tudo pra transformar e vencer grande parte dos problemas hoje vivenciados com a unificação da eleição para Conselho Tutelar. Com isso, teremos a grande possibilidade de exigir a formação continuada.

Nesse sentido, a prática dos Conselhos Tutelares e dos Conselhos Municipais será muito importante para a formação. Dessa forma, um processo de formação não pode contar com conselhos que só existam no papel. Ele precisa da prática de conselhos que existam para formar um conhecimento.

Vejam só essa comparação: a prática, a construção do conhecimento jurídico no Brasil é secular. Temos a prática do conhecimento de várias atividades que são seculares, que foram sendo cumulativamente registradas. As pessoas foram escrevendo suas experiências, e seus registros nos possibilitam hoje formar um médico, um advogado, um psicólogo, um engenheiro, um filósofo, um pedagogo. No campo das atividades dos conselhos nós não tínhamos essa prática e, por consequência, registro de experiência prática.

Hoje empossamos um juiz com pouco mais de vinte e cinco anos. Imagina um menino ser juiz? Isso era inadmissível até pouco tempo na nossa tradição. Hoje nós admitimos, por quê? Porque temos acúmulo de práticas na justiça que fazem com que um profissional rapidamente, em seis meses, prepare esse jovem para exercer a justiça. E nós não tínhamos isso no campo do Conselho Tutelar e no Conselho de Direitos. Não temos. Quem escreveu 
sobre isso? Grande parte não era ou foram conselheiros. Nós não temos conselheiros de fato. Por que não somos? Por que somos conselheiros de papel. Não nos é permitido sermos professores de papel, pesquisadores de papel. Em algumas cidades, os conselhos nem foram criados no papel e não existem nem no papel.

Nós existimos! E, às vezes, o fato de a pessoa ser nomeada, não quer dizer que ela vai ser de papel. No papel qualquer um faz suas funções. Tem Conselho Tutelar e tem conselheiro de papel? Tem muitos Conselhos onde tem três trabalhando e dois que não trabalham, e dois que flauteiam. Existem situações piores em que uma conselheira trabalha e outros quatro assistem de camarote. Dessa forma, Conselho de papel não é só aquele que está na relação que o prefeito manda dos empossados para Brasília, o Conselho de papel também é aquele em que as pessoas que foram nomeadas para exercerem as suas funções não o fazem. 0 Ministério Público, cujas funções não estão somente no papel, pode fazer a fiscalização desses processos.

Quando o conselho é de papel e denuncia uma falha, não existe a fiscalização do Ministério Público, mas também não existe a fiscalização da sociedade. Por isso, nós temos que realmente formar e transformar nossas práticas nesse país. As instituições são formadas por pessoas que, por meio de suas ações, transformam as suas instituições ou as deformam. Quando se formam pessoas que compõem os Conselhos, estamos investindo nos conselheiros. O conselho está capacitado porque os conselheiros foram capacitados.

O que se deve buscar em uma formação continuada, num sentido mais geral, é ampliar a visão do conhecimento e a competência técnica dos colegiados, com vistas a instituir o conhecimento recheado de compromisso ético, com a cidadania da criança e do adolescente, não só no território de atuação. Ampliar visão, conhecimento e competência, é ver, pensar e agir. Não devemos formar alguém para executar uma receita de bolo. Temos que ampliar o conhecimento, a visão e a competência. 
Discutir os princípios básicos da organização e divisão da renda da administração pública implica conhecer, discutir e analisar a legislação; reconhecer o processo de organização e funcionamento de um conselho; identificar as diferentes formas de financiamento das políticas; estabelecer um conjunto de estratégias para o processo de elaboração e acompanhamento da aplicação das políticas públicas.

O que deve conter a formação? A Constituição Federal envolve administração do Estado, descentralização de política administrativa, autonomia, instrumentos de controle social, a Convenção Internacional, os protocolos, o Estatuto e as outras leis. Conhecimento sobre a organização interna dos Conselhos, o processo de criação dos Conselhos, as contribuições a partir do trabalho, as políticas públicas dirigidas ao atendimento e a promoção dos direitos da criança e do adolescente no seu território. Além das políticas, ações, programas e serviços disponíveis, os indicadores sociais trazem os serviços que atendem aos direitos da criança e do adolescente. Isso é o básico e, sendo assim, a formação tem que oferecer todo esse conhecimento.

É possível ser conselheiro do dia para a noite? Não dá! Na área do direito da criança não dá para se tornar conselheiro de repente. Vamos ser bem realistas nisso. Agora, como fazer isso? Existem diversas formas. Eu defendo um movimento bem híbrido, que traga várias possibilidades. Cursos modulares presenciais, com carga horária de 20 horas; módulos a distância e interação com os ministrantes. Essa tecnologia é importante, porque o professor nem sempre pode estar junto, todo o tempo, portanto ela ajuda na comunicação mesmo se você estiver na sua cidade e o professor em outra.

Outros recursos que podem e devem ser utilizados na formação de conselheiros são Seminários, Jornadas temáticas, Oficinas (oficinas é o que o pessoal mais solicita), Colóquios, Fóruns Eletrônicos, Biblioteca eletrônica, Suporte técnico permanente.

Muito ainda poderia falar. Mas devido ao tempo, eu agradeço a atenção e a paciência de todos. Muito obrigado! 